\title{
COMPOSTEIRA EXPERIMENTAL EM AMBIENTE INSTITUCIONAL: INSTRUMENTO DE EDUCAÇÃO AMBIENTAL E BUSCA DA SUSTENTABILIDADE
}

\section{Ana Maria Maniero Moreira ${ }^{1}$}

Lígia de Lima Carvalho²

\section{Wanda M. Risso Günther ${ }^{3}$}

RESUMO: Este trabalho é um estudo de caso e trata das experiências resultantes da implantação, operação e monitoramento de composteira caseira em ambiente institucional, alimentada com resíduos orgânicos aí gerados. O método de compostagem simplificada utilizado envolveu degradação aeróbia de resíduos diretamente sobre o solo, revolvimento semanal para aeração e controle de parâmetros: quantidade e tipo de matéria orgânica, temperatura, umidade e produção de composto. A primeira leira foi implantada em março/2009 e são aproveitados os resíduos orgânicos gerados nas copas de diversos setores da instituição e as folhas e restos de podas oriundos do jardim. Desde então, até julho/2010, foram reaproveitados um total de $2214 \mathrm{~kg}$ de resíduos orgânicos putrescíveis, além de restos de plantas. O projeto de compostagem propiciou o desenvolvimento de ações indutoras de sustentabilidade: reutilização de materiais (potes descartáveis), produção de composto orgânico para o jardim; conscientização e mobilização de diversos setores frente a ações de educação ambiental; divulgação de ações sustentáveis por meio de visitas monitoradas à composteira e distribuição de amostras de composto à comunidade; além de desviar os resíduos compostados de seu fluxo normal, cuja disposição final seria o aterro

\footnotetext{
${ }^{1}$ Médica, Faculdade de Saúde Pública/USP, mestranda. E-mail: anamaria.fsp@usp.br

2 Estagiária, Faculdade de Saúde Pública/USP, graduanda em Ciências Biológicas. E-mail: ligialcarvalho@yahoo.com.br

${ }^{3}$ Engenheira Química, Faculdade de Saúde Pública/USP, professora. E-mail: wgunther@usp.br
} 
sanitário. A compostagem caseira mostrou-se um meio viável e ambientalmente sustentável de recuperação de resíduos orgânicos institucionais e de motivação para práticas sustentáveis na instituição. Como parte do Programa USP Recicla na Faculdade de Saúde Pública, o projeto tornou-se exemplo de como ações simples podem contribuir na busca da sustentabilidade institucional, mesmo em ambientes que, a princípio, parecem impróprios para tal fim.

Palavras-chave: Resíduos Sólidos. Compostagem caseira. Composto orgânico.

\section{INTRODUÇÃO}

A geração crescente e diversificada de resíduos sólidos urbanos (RSU) e a disposição final dos mesmos sempre foi motivo de preocupação para os setores responsáveis por seu gerenciamento. Seu destino inadequado resulta em impactos ambientais e riscos à saúde e, atualmente, é um dos principais problemas de poluição urbana.

A composição dos RSU pode variar de comunidade para comunidade, dependendo do número de habitantes do local, hábitos e costumes da população, poder aquisitivo, variações do clima, nível educacional e de desenvolvimento, variando ainda para a mesma comunidade conforme as estações do ano (FUNASA, 2006).

Segundo a Organização Pan-americana da Saúde, na composição dos RSU dos países da América Latina e Caribe predominam os resíduos orgânicos putrescíveis, com valores entre 50 e $70 \%$ em peso (média em torno de 56\%), enquanto a concentração de resíduos recicláveis é calculada em torno de 25\% (OPAS, 2005).

De acordo com a Fundação Nacional de Saúde (FUNASA, 2006), de um modo geral, os resíduos sólidos são constituídos de substâncias: facilmente degradáveis (restos de comida, sobras de cozinha, folhas, capim, cascas de frutas, animais mortos e excrementos); moderadamente degradáveis (papel, papelão e outros produtos celulósicos); dificilmente 
degradáveis (trapo, couro, pano, madeira, borracha, cabelo, pena de galinha, osso, plástico) e não degradáveis (metal não ferroso, vidro, pedras, cinzas, terra, areia, cerâmica).

Quando os resíduos facilmente degradáveis não recebem destinação adequada, sua disposição a céu aberto pode causar poluição das águas e do solo, incômodos decorrentes do odor, além de atrair e propiciar a proliferação de roedores e vetores de importância sanitária (FUNASA, 2006).

Entre os métodos de tratamento de resíduos orgânicos destaca-se a compostagem.

A compostagem é um processo biológico, que consiste na degradação controlada de matéria de origem orgânica, por ação de microrganismos, em ambiente propício quanto à umidade, temperatura e disponibilidade de oxigênio, resultando na produção de dióxido de carbono, água, minerais e uma matéria orgânica estabilizada, denominada adubo ou composto orgânico.

O composto é produzido sobrepondo-se camadas de diferentes tipos de resíduos formando-se pilhas ou leiras.

O ciclo da compostagem leva em média de 9 a 16 semanas, dependendo do material orgânico utilizado, das condições ambientais e dos cuidados dispensados com a oxigenação e dos controles da umidade e temperatura da leira (EMBRAPA, 2007).

Segundo KIEHL (1985), tanto o excesso quanto o baixo teor de umidade podem prejudicar o processo da compostagem: quando a umidade é excessiva, ocorre a exalação de odores e quando esta se encontra abaixo de $40 \%$ há inibição da atividade microbiológica.

A compostagem é um processo exotérmico devido ao metabolismo dos microrganismos, os quais são responsáveis pelo aumento da temperatura das leiras..O ideal é que no processo inicial de decomposição a temperatura fique em torno de $60^{\circ} \mathrm{C}$ (insuportável ao toque). Com a decomposição dos materiais orgânicos a temperatura vai decrescendo, girando em torno de $40^{\circ} \mathrm{C}$. (EMBRAPA, 2007)

Variações desses limites podem ocasionar a queima ou o apodrecimento do material, perdendo com isso o seu valor nutritivo para as plantas (PARÁ, 2003)

Outro importante fator é a proporção de carbono $(C)$ e nitrogênio $(N)$ na mistura, visto que irá regular a ação dos microrganismos na transformação do "lixo" em adubo. A relação 
$\mathrm{C} / \mathrm{N}$ inicial deve manter-se em torno de $30 / 1$, ou seja, os microrganismos precisam de 30 partes de carbono para cada parte de nitrogênio. O nitrogênio é encontrado em abundância no lixo doméstico orgânico (legumes, hortaliças, cascas e restos de frutas, folhas verdes, borra de café) e o carbono em folhas de jardim, restos de poda e grama secos.

De acordo com o Ministério da Agricultura, Pecuária e Abastecimento, não devem ser utilizados no processo de compostagem materiais que contenham gordura, por dificultarem a decomposição, como também restos de carne, para evitar a atração de animais.

Deve-se estabelecer uma rotina de reviramento semanal da leira para que se mantenham boas as condições de temperatura, umidade e oxigenação e evitar a exalação de mau cheiro. Caso existam animais domésticos soltos próximos à leira de compostagem, deve-se cercá-la com telas com arame (EMBRAPA, 2007).

O composto maturado resultante (Figura 1), apresenta uma estrutura semelhante a grãos pequenos, aspecto homogêneo, cor marrom escura, cheiro agradável de terra, temperatura ambiente, $\mathrm{pH}$ neutro próximo de 7 e livre de agentes patogênicos e de sementes de ervas daninhas.

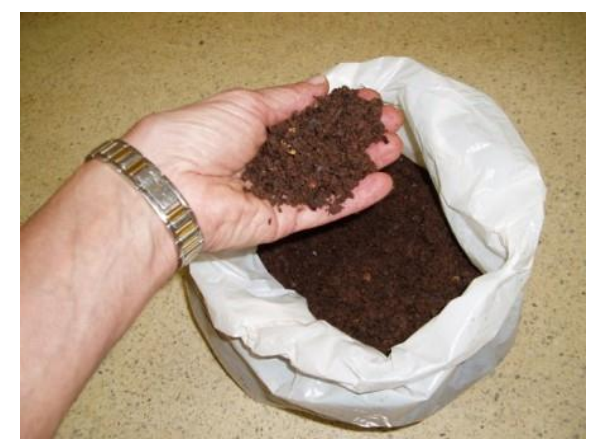

Figura 1 - Composto orgânico maturado

O composto orgânico, quando adicionado ao solo, melhora as suas características físicas, químicas e biológicas, proporcionando mais vida ao solo e melhorias na produção agrícola, sem a necessidade de utilização de fertilizantes sintéticos.

Além de somente possuir elementos naturais em sua composição, ao aproveitarmos uma parcela do lixo comum, estamos diminuindo o volume de resíduos sólidos encaminhado 
aos aterros (e muitas vezes até para vazadouros a céu aberto), contribuindo dessa maneira para a redução de impactos ambientais e para a melhoria da qualidade de vida e de saúde da população.

Para JAHNEL (1997) as vantagens da aplicação do composto no solo são: a presença de nutrientes minerais como nitrogênio, fósforo, potássio, cálcio, magnésio, enxofre e micro nutrientes como ferro, zinco, cobre, manganês, boro e outros; a liberação lenta de nutrientes, ao contrário dos adubos minerais; a formação de pequenos grânulos pela ligação da matéria orgânica com as partículas de areia, limo e argila, os quais auxiliam na retenção e drenagem da água e melhoram a aeração; o aumento do número de minhocas, insetos e microrganismos desejáveis, reduzindo a incidência de doenças de plantas; a neutralização de várias toxinas e imobilização de materiais pesados como cádmio e chumbo, diminuindo a absorção dos mesmos pelas plantas e ainda funciona como solução tampão, impedindo que ocorram mudanças bruscas da acidez e alcalinidade do solo.

Este trabalho tem por objetivo apresentar as experiências resultantes da implantação, operação e monitoramento de uma composteira caseira em ambiente institucional. O projeto de compostagem é uma das ações implantadas pelo Programa USP Recicla na Faculdade de Saúde Pública e é desenvolvido nas dependências da própria faculdade, uma das unidades da Universidade de São Paulo (USP) localizada em área central e de grande complexidade urbana do município de São Paulo.

\section{DESENVOLVIMENTO}

Após levantamento bibliográfico, no qual foram identificadas as melhores práticas de compostagem, as seguintes etapas foram desenvolvidas para a implantação, operação e monitoramento deste projeto:

\subsection{Capacitação teórica e prática dos voluntários}


Primeiramente, foi realizado um curso sobre montagem, operação e monitoramento de compostagem caseira, sob orientação de engenheira agrônoma da Prefeitura Municipal de São Paulo, com a finalidade de capacitar o pessoal envolvido (membros da Comissão USP Recicla, estagiários do projeto, profissional do serviço de jardinagem terceirizado e outras pessoas interessadas) para que pudessem participar do projeto e monitorar adequadamente a composteira.

\subsection{Seleção do tipo de composteira implantada}

O método escolhido foi o de compostagem simplificada, em que a matéria orgânica é acumulada em pilhas sucessivas denominadas leiras, diretamente sobre o solo (Figura 2), o que permite o livre acesso de minhocas. Folhas secas e grama do jardim são intercaladas com os resíduos orgânicos formando camadas na proporção 3:1, sempre finalizadas por camada de folhas, para se evitar a exposição dos orgânicos e, consequentemente, a atração de animais.

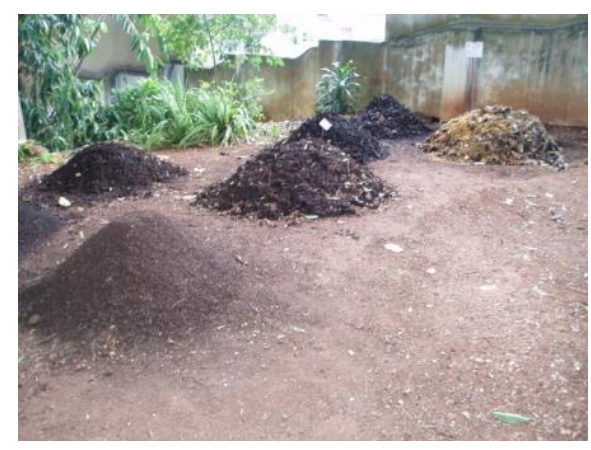

Figura 2 - Leiras de compostagem

\subsection{Escolha da área para instalação da composteira}


Embora houvesse vários espaços disponíveis no terreno da instituição, para evitar uma possível preocupação da comunidade da faculdade com a possibilidade de produção de odores desagradáveis, atração e proliferação de insetos e outros animais vetores de doenças, foi escolhido para a instalação da composteira um ambiente isolado, na divisa do terreno, afastado das atividades habituais, localizado atrás da Creche.

Outros fatores que motivaram esta seleção foram: espaço suficiente para criação de várias leiras e seu fácil revolvimento; proteção do vento e de insolação direta; fácil acesso e presença de pequena declividade do terreno para facilitar a drenagem.

\subsection{Adequação do local e provisão dos equipamentos necessários}

No local selecionado foram instalados pontos de água e de energia e, para a operação da composteira, foram adquiridos equipamentos de jardinagem como enxadas, pás e rastelo.

Uma balança de uso doméstico e um termômetro foram providenciados para o monitoramento, respectivamente, da quantidade de resíduos putrescíveis adicionados, de composto maturado gerado e das temperaturas das leiras e ambiente.

Foram providenciados também mesa, baldes, luvas, facões, tábua de madeira (para a fragmentação dos resíduos orgânicos no local), lona para cobrir as leiras em dias de chuva e peneira para a etapa de refinar o produto final, o que melhora sua qualidade.

Um triturador elétrico foi adquirido e utilizado durante certo tempo. Porém, durante o período de uso deste equipamento, observou-se que o triturador produzia uma massa orgânica compacta e úmida, a qual estava retardando a fase de degradação. Foi decidido, então, retomar a trituração manual. 


\subsection{Acondicionamento, armazenamento e coleta dos resíduos}

O acondicionamento dos resíduos orgânicos nas copas dos departamentos é preferencialmente realizado em potes plásticos descartáveis de sorvete (Figura 3), o que contribui também para o reaproveitamento, mediante reutilização desses materiais.

Os potes são continuamente abastecidos pelos usuários das copas e permanecem armazenados em geladeiras de segunda à sexta-feira, quando, então, são recolhidos e levados para a área da composteira pelos voluntários do projeto.

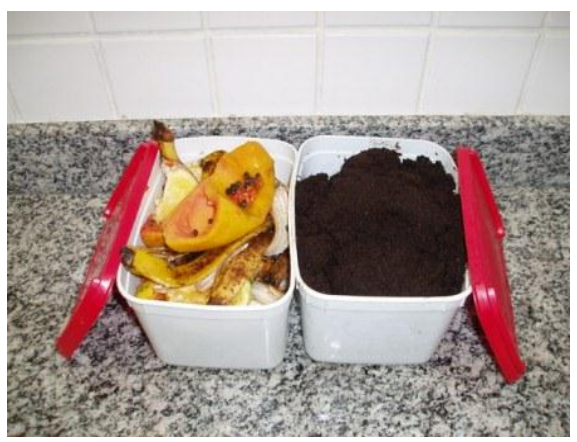

Figura 3 - Reaproveitamento de potes para acondicionamento de resíduos orgânicos

\subsection{Operação da composteira}

A primeira leira foi criada em março/2009, utilizando-se apenas os resíduos orgânicos gerados na Creche Saúde, além de folhas e restos de poda do jardim da própria faculdade.

Atualmente, a composteira conta também com os resíduos orgânicos provenientes das copas dos departamentos e central (6) e de outros setores como Biblioteca, Laboratórios e Centro de Saúde, localizados nas dependências da faculdade. 


\section{Periódica Eletrânica

Dos resíduos facilmente degradáveis, gerados nesses locais são aproveitados apenas cascas e sobras de frutas, vegetais e legumes, além de borra de café. Não são utilizados sobras de comida e alimentos processados.

A adição semanal de matéria orgânica sempre é feita na leira em processo de degradação mais ativo. No início de cada mês, uma nova leira de compostagem é criada, o que acarreta a existência de leiras em diferentes estágios de decomposição.

Os resíduos são depositados em camadas, na proporção de 3/4 de folhas para 1/4 de orgânicos putrescíveis, finalizando-se com as folhas para que não ocorra a atração de vetores e para minimizar a exalação de possíveis odores desagradáveis.

Para a manutenção da presença de oxigênio nas leiras, realiza-se o revolvimento uma vez por semana, visando à manutenção do processo de degradação aeróbia e evitar a produção de odores.

Semanalmente, uma equipe de voluntários mede a temperatura e avalia a umidade das leiras, promove o revolvimento das leiras mais recentes (Figura 4) e realiza a fragmentação manual, pesagem e integração dos resíduos orgânicos coletados durante aquele período. Nos períodos de chuva, utiliza-se uma lona para cobrir as leiras e em épocas secas há necessidade de rega. A avaliação da umidade ocorre por análise sensorial, sendo que o ideal é que o composto nunca atinja valores menores que $40 \%$.

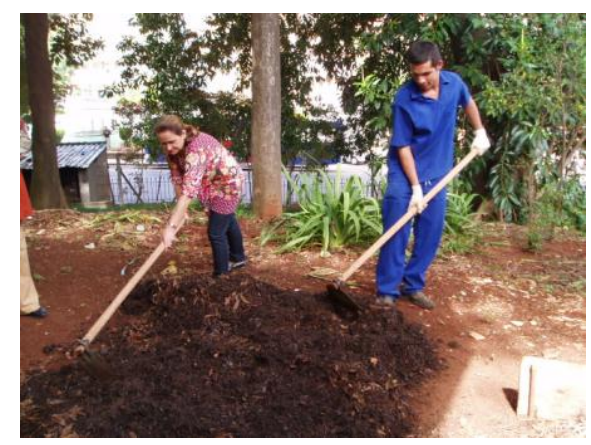

Figura 4 - Revolvimento semanal das leiras

Quando fica comprovada a finalização do processo de degradação, todo o composto gerado é peneirado (Figura 5) e dividido em dois tipos de produto, sendo aquele que passa pela peneira classificado como de melhor qualidade. 


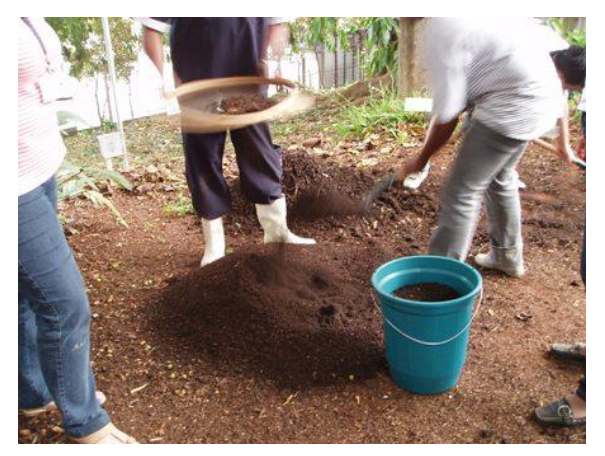

Figura 5 - Passagem pela peneira

O produto final é pesado e, em seguida, estocado de 2 formas: a granel para ser utilizado como fertilizante nos vasos, horta de hortaliças da creche e jardins da faculdade ou ensacado, em embalagens de aproximadamente $400 \mathrm{~g}$ (Figura 6), para ser distribuído aos visitantes da composteira e participantes de eventos.

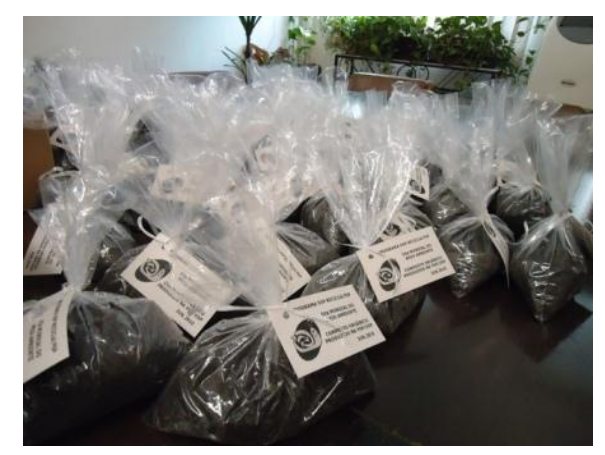

Figura 6 - Composto embalado

A intenção do programa é, posteriormente, expandir o reaproveitamento dos resíduos orgânicos, incorporando também aqueles gerados nos 2 restaurantes que funcionam nas dependências da faculdade (universitário e terceirizado) e que servem, em média e respectivamente, 400 e 230 refeições diárias.

\subsection{Controle de parâmetros quantitativos e qualitativos}


$\mathrm{Na}$ operação da composteira, os parâmetros controlados são:

a. Quantidade de matéria orgânica coletada e incorporada à leira semanalmente, por meio da pesagem da massa desses resíduos;

b. Temperatura ambiente e das leiras em processo de degradação ativo antes do revolvimento semanal, utilizando-se termômetro laboratorial;

c. Umidade: avaliação sensorial, apertando-se o composto na mão para perceber a presença de água livre;

d. Quantidade de composto orgânico produzido;

e. Registro fotográfico: acompanhamento cronológico dos procedimentos operacionais e das atividades desencadeadas com a produção, distribuição e uso do composto orgânico (Figura 7).

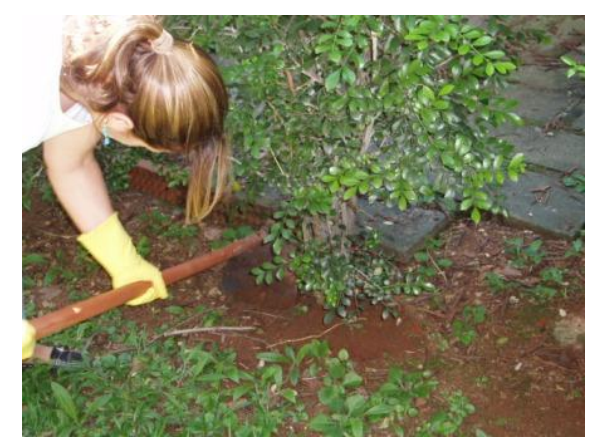

Figura 7 - Utilização do composto no jardim

\section{RESULTADOS}

A mobilização de pessoas dos departamentos da faculdade e sua integração ao projeto permitiram um aumento gradual da coleta mensal de resíduos orgânicos.

Em março de 2009, primeiro mês de operação, a composteira recebeu $36 \mathrm{~kg}$ de orgânicos. No segundo mês (abril), a participação se intensificou e houve um acréscimo de aproximadamente $58 \mathrm{~kg}$, 
Conforme a Tabela 1, durante o ano de 2009, aproximadamente uma e meia tonelada de resíduos putrescíveis foram segregados na FSP para a produção de adubo orgânico.

Tabela 1. Quantidade de resíduos orgânicos putrescíveis adicionados às leiras em 2009

\begin{tabular}{cc}
\hline Mês & Resíduos orgânicos $\mathbf{( k g )}$ \\
\hline Março & 36,0 \\
Abril & 93,5 \\
Maio & 94,2 \\
Junho & 110,0 \\
Julho & 203,0 \\
Agosto & 215,0 \\
Setembro & 294,7 \\
Outubro & 228,0 \\
Novembro & 136,5 \\
Dezembro * & 88,0 \\
\hline TOTAL & $\mathbf{1 4 9 8 , 9}$ \\
\hline
\end{tabular}

Nota: * período de férias

As quantidades incorporadas, mensalmente, no primeiro semestre de 2010 são apresentadas na Tabela 2.

Tabela 2. Quantidade de resíduos orgânicos putrescíveis adicionados às leiras em 2010

\begin{tabular}{cc}
\hline Mês & Resíduos orgânicos $\mathbf{( k g )}$ \\
\hline Fevereiro & 37,5 \\
Março & 135,7 \\
Abril & 132,5 \\
Maio & 138,5 \\
Junho & 116,5 \\
Julho & 154,3 \\
\hline TOTAL & $\mathbf{7 1 5 , 0}$ \\
\hline
\end{tabular}


Devido ao período de férias, a coleta foi suspensa em janeiro e reiniciada gradativamente em fevereiro. Nos meses de abril, maio e junho, a USP passou por um período de greve, o que afetou o funcionamento de alguns setores e contribuiu para a redução da quantidade de orgânicos gerados na unidade.

Como resultado, a massa total de resíduos orgânicos putrescíveis incorporados à composteira desde sua implantação foi de $2214 \mathrm{Kg}$. Isto significa que mais de duas toneladas de resíduos gerados na instituição foram tratados em seu próprio território e desviados do fluxo normal que tem como destino a coleta regular municipal e a disposição em aterro sanitário.

Além disso, calcula-se que a produção de composto orgânico represente 2,6 vezes a quantidade de resíduos orgânicos putrescíveis incorporados à composteira. Isso porque, as folhas e podas de jardim incorporadas, embora não quantificadas, também sofrem degradação e são transformadas em composto orgânico.

Assim sendo, pode-se inferir que a geração média de composto orgânico, somente em 2009 , representou cerca de 3.900 , ou seja, quase 4 toneladas.

Outro parâmetro monitorado é a temperatura. Como o processo é exotérmico, é esperado que ocorra aumento da temperatura, principalmente nos primeiros dias do processo de degradação. Segundo a bibliografia de referência, a temperatura interna de uma leira pode chegar até $60^{\circ} \mathrm{C}$. Porém, nossas leiras, por serem de pequenas dimensões e em formato cônico, têm apresentado temperaturas que variaram de 18 a $60{ }^{\circ} \mathrm{C}$ (Figuras $8 \mathrm{e}$ 9) , dependendo das variações climáticas do dia em que é realizada a medição.

Figura 8 - Temperatura (ํ) semanal da leira em fase de degradação mais ativa (2009) 


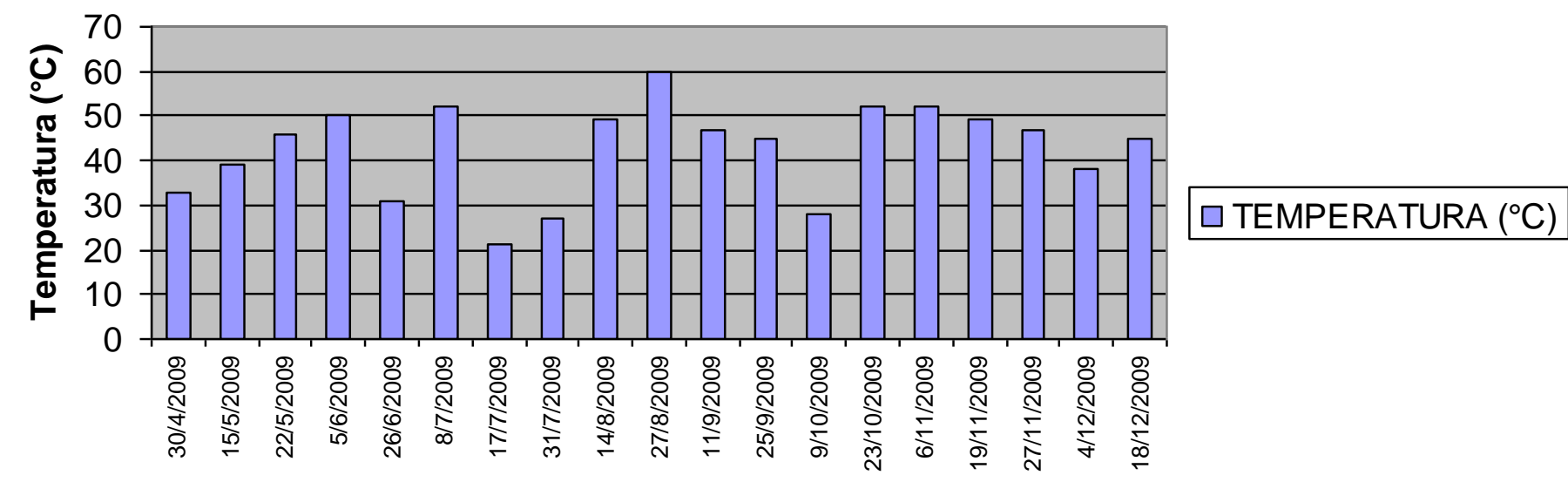

Datas

Para um melhor acompanhamento das variações climáticas, desde o início de 2010, vem sendo também mensurada a temperatura ambiente. Neste ano, a temperatura ambiente variou de 16 a $29^{\circ} \mathrm{C}$ e a temperatura da leira em fase de degradação mais ativa de 25 a $60^{\circ} \mathrm{C}$. (Figura 9).

Figura 9 - Temperaturas $\left({ }^{\circ} \mathrm{C}\right)$ da leira em fase de degradação mais ativa e ambiente (2010) 


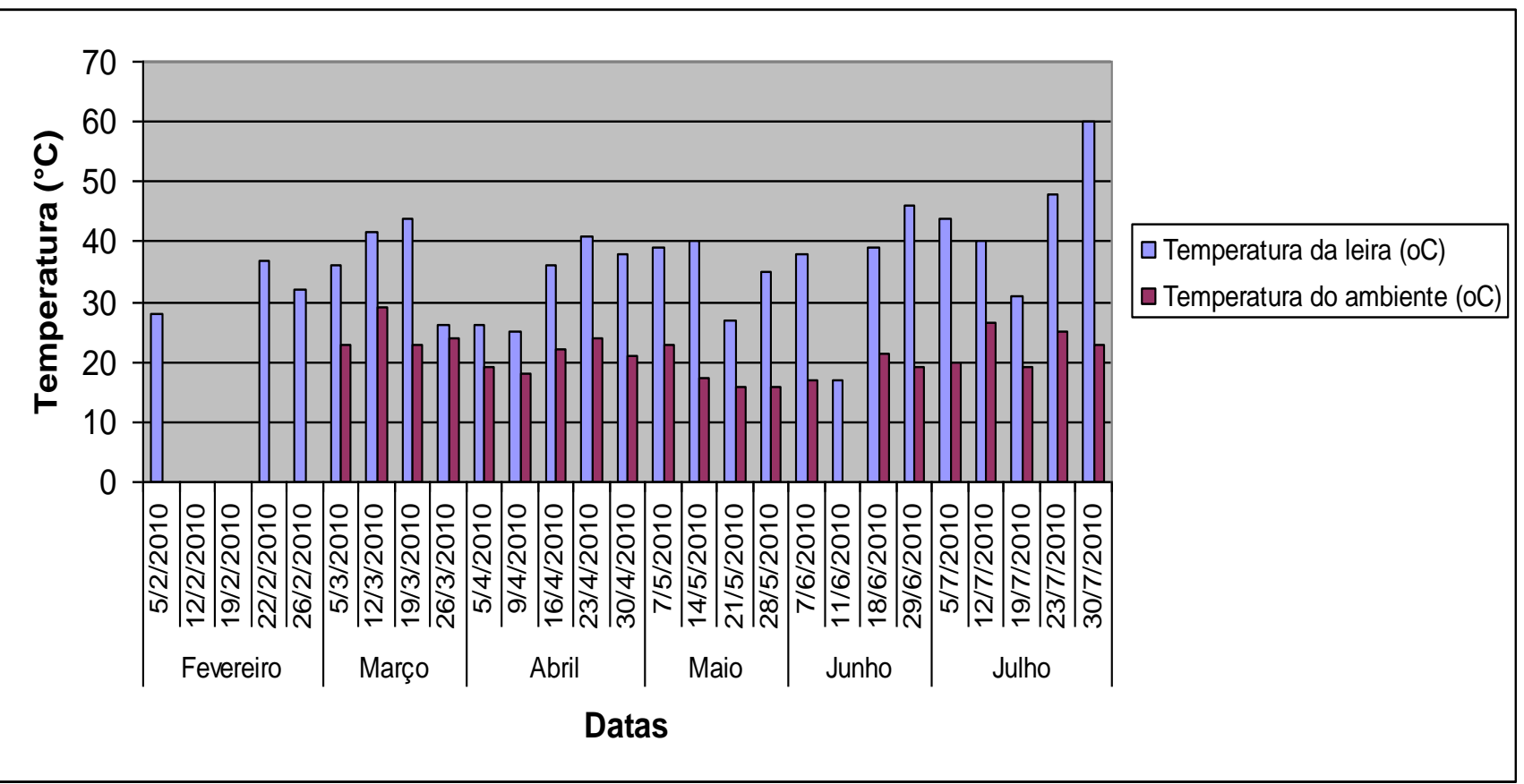

\section{CONCLUSÕES E RECOMENDAÇÕES}

Este projeto propiciou o desenvolvimento de várias ações que induzem à sustentabilidade da instituição FSP/USP, conforme seguem:

a. Conscientização e mobilização da comunidade de diversos setores da faculdade para ações sustentáveis, induzidas por atividades de educação ambiental;

b. Coleta e reaproveitamento de resíduos orgânicos na própria unidade, os quais antes eram destinados para a coleta regular municipal;

c. Economia de espaço físico nos aterros;

d. Reutilização de embalagens descartáveis (potes plásticos de sorvete) para armazenamento dos resíduos orgânicos;

e. Produção de composto orgânico para uso em vasos e no jardim da própria faculdade, em substituição ao adubo químico;

f. Devolução à terra de nutrientes que ela precisa, fechando o ciclo; 


\section{Periódica Sletrânica

g. Divulgação de ações sustentáveis, por meio de visitas monitoradas à composteira, principalmente com as crianças da Creche que participam de trabalho pedagógico dessa natureza;

h. Distribuição de composto orgânico (200 kg), em pacotes individuais (Figura 10), devidamente identificados e com instruções de uso, para visitantes e em eventos, como por exemplo, a comemoração do Dia Mundial do Meio Ambiente;

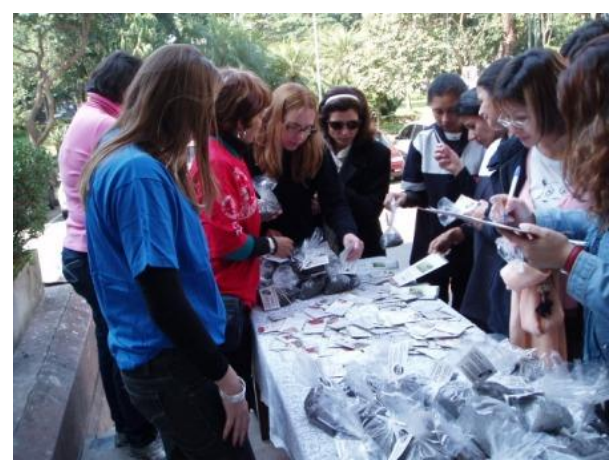

Figura 10 - Distribuição de composto orgânico e sementes na Semana do Meio Ambiente

i. Indução à redução de gastos de gerenciamento municipal dos resíduos sólidos urbanos, mediante a não coleta, transporte e disposição final dos resíduos compostados;

j. Estímulo à cidadania da comunidade da faculdade, ao se buscar a participação social em práticas minimizadoras de resíduos e produtoras de ações sustentáveis, o que, em última análise, trabalha a favor da mudança de atitude pessoal.

As maiores dificuldades encontradas no desenvolvimento deste projeto foram: fortes chuvas ocorridas no primeiro semestre de 2010 , instabilidade do número de voluntários para o revolvimento semanal, falta de locais refrigerados em alguns departamentos para o armazenamento dos orgânicos e falta de recursos financeiros e operacionais para adequar a área da composteira. 
A compostagem caseira mostrou-se um meio viável e ambientalmente sustentável de recuperação de resíduos orgânicos institucionais e de motivação para práticas sustentáveis na instituição.

Como parte do Programa USP Recicla na Faculdade de Saúde Pública (FSP), o projeto tornou-se exemplo de como ações simples podem contribuir na busca da sustentabilidade institucional, mesmo em ambientes que, a princípio, seriam considerados impróprios para tal fim.

Mostrou-se também ser uma prática de fácil operação e controle, que pode ser ampliada dentro da FSP, implantada em ambientes institucionais semelhantes e mesmo em domicílios, como forma de minimização de resíduos e de preservação ambiental.

\section{REFERÊNCIAS}

EMBRAPA. Ministério da Agricultura, Pecuária e Abastecimento. Circular Técnica. Compostagem Caseira de Lixo Orgânico Doméstico. Cruz das Almas, 2005

FUNASA. Fundação Nacional de Saúde. Manual de saneamento. $3^{\underline{a}}$ ed. ver. $1^{1}$ reimpressão. Brasília: Fundação Nacional de Saúde, 2006.

JAHNEL, M. C. Compostagem: a outra metade da reciclagem. São Paulo. IPT/CEMPRE, 1997.

KIEHL, E.J. Manual de compostagem: maturação e qualidade do composto. Piracicaba; USP, 2004.

LAMANNA, S. Compostagem caseira como instrumento de educação ambiental e minimização de resíduos sólidos urbanos. Campos do Jordão, São Paulo. 2008. Disponível em: <http://www.teses.usp.br/teses/disponiveis/90/90131/tde-05052008-111139/>. Acesso em: 26 abr 2010. 


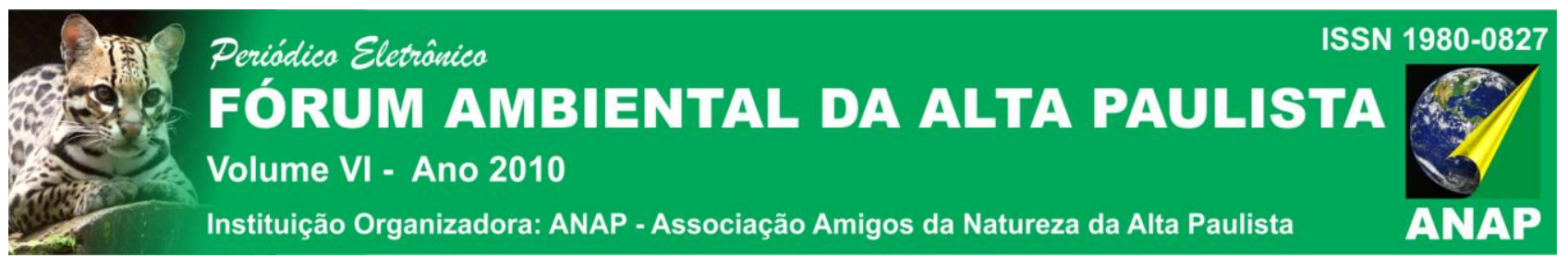

OPAS - Organização Panamericana de Saúde. Informe de la Evaluácion Regional de los Servicios de Manejo de Resíduos Sólidos Municipales em América Latina y El Caribe. Washington, DC. 2005.

PARÁ. Secretaria Executiva de Ciência, Tecnologia e Meio Ambiente. Programa Paraense de Tecnologias Apropriadas. Compostagem: produção de adubo a partir de resíduos orgânicos. Belém: SECTAM, 2003.

SANTOS, R.C.; CAMPOS, J.F.; PINHEIRO, C..D.; TLON, Y.B.; SOUZA, S.R.; BARACHO, M. \& CARMO. E.L. Usinas de Compostagem de Lixo como alternativa viável à problemática dos lixões no meio urbano. Enciclopédia Biosfera, N.02, 2006 